\title{
The intraocular pressure-lowering properties of intravenous paracetamol
}

This article was published in the following Dove Press journal:

Clinical Ophthalmology

13 July 2016

Number of times this article has been viewed

\section{Henning van den Heever David Meyer}

Division of Ophthalmology, Faculty of Medicine and Health Sciences, Stellenbosch University, Cape Town, South Africa
Correspondence: Henning van den Heever

Division of Ophthalmology, Faculty of Medicine and Health Sciences,

Stellenbosch University,

PO Box 24I, Cape Town, 8000 , South Africa

Tel +27 2l 9389380

Fax +27219385511

Email henningjv@yahoo.com
Aim: The aim of this paper was to investigate the intraocular pressure (IOP)-changing properties of a single standard dose of intravenous (IV) paracetamol and compare it to that of topical timolol, oral acetazolamide, and no treatment.

Methods: A prospective, randomized, investigator-blind, parallel-group study was conducted in 73 eyes of 52 subjects. Subjects received a single dose of IV paracetamol $(1 \mathrm{~g})$, oral acetazolamide ( $250 \mathrm{mg}$ ), topical timolol ( $0.5 \%$, one drop), or no treatment. Baseline IOP was measured, and the measurement was repeated at 1,2,4, and 6 hours after treatment.

Results: Paracetamol reduced IOP from baseline by $-10.8 \%$ (95\% confidence interval $[\mathrm{CI}]:-4.9 \%$ to $-16.8 \%, P=0.146)$ at 1 hour, $-13.3 \%$ (95\% CI: $-8.3 \%$ to $-18.4 \%, P=0.045)$ at 2 hours, $-11.8 \%(95 \% \mathrm{CI}:-5.5 \%$ to $-18.4 \%, P=1.000)$ at 4 hours, and $-23.9 \%(95 \%$ CI: $-17.8 \%$ to $-30.1 \%, P=0.006)$ at 6 hours after treatment. In the no-treatment group, the change was $-2.9 \%$ (95\% CI: $+1.0 \%$ to $-6.7 \%, P=$ referent) at 1 hour, $-2.1 \%$ ( $95 \% \mathrm{CI}:+2.9 \%$ to $-7.2 \%, P=$ referent $)$ at 2 hours, $-7.6 \%(95 \% \mathrm{CI}:-3.9 \%$ to $-11.2 \%, P=$ referent $)$ at 4 hours, and $-6.9 \%(95 \% \mathrm{CI}:-3.6 \%$ to $-10.2 \%, P=$ referent $)$ at 6 hours. Acetazolamide reduced IOP by $-18.8 \%(95 \% \mathrm{CI}:-12.7 \%$ to $-24.8 \%, P=0.000)$ at 1 hour, $-26.2 \%(95 \% \mathrm{CI}:-18.2 \%$ to $-34.2 \%, P=0.001)$ at 2 hours, $-24.6 \%(95 \% \mathrm{CI}:-16.9 \%$ to $-32.3 \%, P=0.000)$ after 4 hours, and $-26.9 \%$ (95\% CI: $-19.6 \%$ to $-34.3 \%, P=0.000) 6$ hours after treatment. Timolol reduced IOP by $-31.2 \%(95 \% \mathrm{CI}:-26.7 \%$ to $-35.7 \%, P=0.000)$ at 1 hour, $-27.7 \%(95 \% \mathrm{CI}:-20.7 \%$ to $-34.8 \%, P=0.000)$ at 2 hours, $-28.7 \%(95 \% \mathrm{CI}:-21.1 \%$ to $-36.2 \%, P=0.000)$ at 4 hours, and $-21.3 \%(95 \% \mathrm{CI}:-13.4 \%$ to $-30.0 \%, P=0.030)$ at 6 hours after treatment. The average change in IOP for the no-treatment group was $-4.8 \%(95 \% \mathrm{CI}:-2.6 \%$ to $-6.9 \%, P=$ referent). It was $-15.7 \%$ (95\% CI: $-9.3 \%$ to $-22.1 \%, P=0.021)$ for paracetamol, $-23.1 \%$ (95\% CI: $-16.4 \%$ to $-29.8 \%, P=0.000)$ for acetazolamide, and $-25.3 \%$ for the timolol group (95\% CI: $-19.4 \%$ to $-31.2 \%, P=0.000)$. The maximal change in IOP for the no-treatment group was $-9.2 \%(95 \%$ CI: $-3.2 \%$ to $-15.3 \%, P=$ referent). It was $-25.9 \%$ (95\% CI: $-16.6 \%$ to $-35.2 \%, P=0.009)$ for paracetamol, $-33.8 \%$ (95\% CI: $-25.5 \%$ to $-42.1 \%, P=0.000)$ for acetazolamide, and $-36.8 \%$ ( $95 \%$ CI: $-31.0 \%$ to $-42.5 \%, P=0.000$ ) for the timolol group.

Conclusion: Intravenously administered paracetamol shows IOP-lowering properties over the first 6 hours after administration. Clinicians performing IOP measurements in patients who have received IV paracetamol in the preceding 6 hours should interpret these measurements with caution. Further studies are needed to investigate the IOP-changing properties of paracetamol.

Keywords: AM404, anandamide, endocannabinoid, ocular hypotensive

\section{Introduction}

Paracetamol has already shown theoretical and clinical potential as an ocular hypotensive possibly as a result of its interactions with the endocannabinoid system (ECS). ${ }^{1-3}$ Intravenous (IV) paracetamol is often used in the perioperative period as an opioid-sparing analgesic in the adult and pediatric population, and ophthalmologists 
may encounter patients, during procedures and thereafter, who have recently received IV paracetamol. ${ }^{4,5}$ The intraocular pressure (IOP)-lowering properties of anesthetic gasses, and other anesthetic agents, have been well studied, and clinicians interpret IOP measurements taken after their administration with caution. ${ }^{6,7}$

IV paracetamol has a proven high analgesic potency and rapid analgesic effect which begged the question of whether it might also result in a change in IOP in accordance with its interaction with the ECS. ${ }^{4}$

The exact mechanism of action of paracetamol is after 137 years still elusive, although we do know that it at least inhibits the activity of enzymes cyclooxygenase- 1 and cyclooxygenase- 2 and reduces the synthesis of prostaglandins in the central nervous system. ${ }^{8}$

The ECS is a system of neurotransmitters and receptors with a remarkable representation in many human tissues including the eye. ${ }^{9-13}$ In 2005, it was molecularly proven that paracetamol acts as a prodrug for the indirect cannabinomimetic AM404. Paracetamol is deacetylated in the brain and spinal cord to $p$-aminophenol, and with the action of fatty acid amide hydrolase undergoes conjugation with arachidonic acid to form AM404. This finding by Högestätt et al and Ottani et al subsequently expanded the knowledge of the mechanism of action of paracetamol by indicating that it stimulates the ECS by increasing the levels of anandamide through reuptake inhibition by AM404. ${ }^{1,2}$ Anandamide is a potent ocular hypotensive, and the question arises as to whether paracetamol would, as other cannabinomimetics do, also reduce IOP. ${ }^{12,13}$

Topical timolol and oral acetazolamide are regarded as the gold standard topical and oral hypotensive agents, respectively, and are both well studied. Clinicians expect to observe a certain level of reduction in IOP in the few hours after their administration. How their IOP-changing properties in the first 6 hours after administration compare with that of paracetamol has not previously been compared. ${ }^{14}$ The main reason for including these comparisons into the study was to give clinical perspective to any possible change in IOP.

To our knowledge, this is thus the first study to investigate the IOP-changing properties of a single standard dose of IV paracetamol in comparison with that of oral acetazolamide, topical timolol, and no treatment. The study would not pursue an investigation into the therapeutic efficacy of IV paracetamol as an IOP-lowering agent.

\section{Materials and methods}

The study was approved by the Human Research Ethics Committee of the Faculty of Medicine and Health Sciences of the Stellenbosch University, Cape Town, and adhered to the tenets of the Declaration of Helsinki. Proper written informed consent was obtained from all participants.

A general physical and full ocular examination was performed on all participants.

Inclusion criteria were consenting adults of any sex and ethnicity of 18-75 years of age with a body weight $>40 \mathrm{~kg}$ and body mass index (BMI) $18.5-37 \mathrm{~kg} / \mathrm{m}^{2}$ inclusive.

External exclusion criteria were the following: known hypersensitivity or idiosyncratic reactions to paracetamol, acetazolamide, or timolol; use of paracetamol or any systemic medications (including $\beta$-blockers) known to lower IOP, within 4 weeks of the study; any known clinically significant systemic (eg, gastrointestinal, hepatic, or renal) disease or other condition known to interfere with the absorption, distribution, metabolism, or excretion of drugs; COPD, asthma, or cardiac contraindications for $\beta$-blocker use; pregnancy or breastfeeding; females of childbearing potential not using medically accepted contraceptive measures; participation in a clinical study of any investigational product 1 month prior to the study or during the study; and the presence of an uncontrolled psychiatric condition.

Ocular exclusion criteria were the following: baseline IOP $\geq 22 \mathrm{mmHg}$ or IOP $\leq 10 \mathrm{mmHg}$, history of glaucoma, signs of glaucomatous optic neuropathy irrespective of IOP (assessed by disc appearance, IOP, and if indicated, optical coherence tomography analysis of optic nerve rim and retinal nerve fiber layer [Carl Zeiss Meditec AG, Jena, Germany] and formal 24-2 visual field analysis [Carl Zeiss Meditec AG]), iridocorneal angles less than grade 3 as with Schaefer's method, or the presence of peripheral anterior synechiae as determined with gonioscopy; contact lenses worn within 3 weeks of starting of study; ocular disease excluding uncomplicated cataract; and previous ocular surgery or trauma in the study eye.

Participants were assigned to the four treatment arms through ratio randomization with a third of eyes each to the paracetamol and no-treatment groups, and a sixth of eyes each to the acetazolamide and timolol groups.

The no-treatment group received no treatment. The paracetamol group received a single dose of $1 \mathrm{~g}$ IV paracetamol (Perfalgan $^{\circledR}$; Bristol-Myers Squibb, New York City, NY, USA). The acetazolamide group received a single oral dose of 250 mg acetazolamide (Diamox ${ }^{\circledR}$; Litha Pharma, Midrand, South Africa). The timolol group received a single drop of $0.5 \%$ timolol maleate (Glaucosan ${ }^{\circledR}$; Sandoz International GmbH, Holzkirchen, Germany) followed by 2 minutes of punctal occlusion. Participants were admitted to a general 
ophthalmology hospital ward and subjected to the same hospital diet and low level of physical activity.

IOP was measured with a calibrated Goldmann applanation tonometer (Haag-Streit ${ }^{\circledR}$ AT-900, Haag-Streit, Koeniz, Switzerland) by a single observer $(\mathrm{HvdH})$ experienced in applanation tonometry. The observer was masked to participant's treatment regimens, and IOP measurements were recorded. This was done by appropriately adjusting the tonometer dial to the estimated value and allowing a second observer to record IOP values and then scrambling the tonometer dial thereafter. For an IOP reading to be accepted as valid, two subsequent readings had to be $<2 \mathrm{mmHg}$ apart. The average of these two valid measurements was calculated and used as the final value.

IOP was again measured at 1, 2, 4, and 6 hours after treatment.

Primary outcomes included percentage change in IOP from baseline at 1, 2, 4, and 6 hours after treatment for each of the four groups. For every eye, the average and maximal percentage changes in IOP were calculated.

\section{Statistical analysis}

IBM SPSS version 23 was used for analysis. A $P$-value $<0.05$ was considered as statistically significant. One-way analysis of variance testing was used to compare mean values between the four groups, with Bonferroni-adjusted post hoc tests. Pearson's chi-square tests were used to compare proportions between the four groups. Multilevel mixed linear regression models were used to assess the determinants of change in IOP over time while adjusting for age, BMI, and sex. The interaction between time and treatment group was taken as the differential treatment effect over time.

\section{Results}

\section{Demographic profile}

Demographic results are presented in Table 1. Ten participants were excluded from the study, prior to observation, because of oral paracetamol and/or oral $\beta$-blocker use 4 weeks prior to or during the study period. One subject voluntarily withdrew from the study, after completion of the hour-2 IOP measurement, because of personal inconvenience. There were no serious adverse events.

Seventy-three eyes of 52 subjects were included in the study. Fifteen eyes were excluded at the 6-hour time point, as their observations were not made close enough to the specific time point. The loss of data for this time point was adequately addressed by statistical modeling.

\section{Change in IOP over time}

There was no significant difference between the baseline IOP of the groups $(P=0.413$; Table 2$)$.

The change in IOP from baseline for the no-treatment group was $-2.9 \%$ at 1 hour, $-2.1 \%$ at 2 hours, $-7.6 \%$ at 4 hours, and $-6.9 \%$ at 6 hours after treatment (Table 2; Figure 1).

Paracetamol reduced IOP from baseline by $-10.8 \%$ $(P=0.146)$ at 1 hour, $-13.3 \%(P=0.045)$ at 2 hours, $-11.8 \%$ $(P=1.000)$ at 4 hours, and $-23.9 \%(P=0.006)$ at 6 hours after treatment.

In the acetazolamide group, the reduction was $-18.8 \%$ $(P=0.000)$ at 1 hour, $-26.2 \%(P=0.000)$ at 2 hours, $-24.6 \%$ $(P=0.001)$ at 4 hours, and $-26.9 \%(P=0.000)$ at 6 hours after treatment.

Timolol reduced IOP by $-31.2 \%(P=0.000)$ at 1 hour, $-27.7 \%(P=0.000)$ at 2 hours, $-28.7 \%(P=0.000)$ at 4 hours, and $-21.3 \%(P=0.030)$ at 6 hours after treatment.

\section{Average change in IOP}

The average change in IOP from baseline over the first 6 hours after treatment for the no-treatment group was $-4.8 \%$ (Table 2; Figure 2). It was $-15.7 \%(P=0.021)$ for paracetamol, $-23.1 \%(P=0.000)$ for acetazolamide, and $-25.3 \%$ $(P=0.000)$ for timolol. There was no statistically significant

Table I Descriptive statistics summary of demographics and number of participants in each group with $( \pm)$ standard deviation

\begin{tabular}{|c|c|c|c|c|}
\hline \multirow[t]{2}{*}{ Characteristic } & \multirow{2}{*}{$\begin{array}{l}\text { No Treatment } \\
\mathrm{n}=24\end{array}$} & \multirow{2}{*}{$\begin{array}{l}\text { Paracetamol } \\
\mathrm{n}=20\end{array}$} & \multirow{2}{*}{$\begin{array}{l}\text { Acetazolamide } \\
\mathrm{n}=17\end{array}$} & \multirow{2}{*}{$\frac{\text { Timolol }}{n=12}$} \\
\hline & & & & \\
\hline Male & 10 & 9 & 7 & 4 \\
\hline Female & 14 & 11 & 10 & 8 \\
\hline Black & 9 & 3 & 7 & 2 \\
\hline Mixed race & 12 & 14 & 9 & 9 \\
\hline Caucasian & 3 & 3 & I & I \\
\hline Age (years) & $43 \pm I 5$ (range, $22-75)$ & $61 \pm 13$ (range, 29-74) & $57 \pm I 5$ (range, 26-74) & $60 \pm I 5$ (range, 24-7I) \\
\hline Weight (kg) & $69 \pm 15$ (range, 5I-102) & $69 \pm 10$ (range, 56-96) & $72 \pm 17$ (range, 46-99) & $72 \pm 19$ (range, 40-106) \\
\hline BMI $\left(\mathrm{kg} / \mathrm{m}^{2}\right)$ & $26 \pm 5$ (range, $21-37$ ) & $26 \pm 4$ (range, 20-32) & $27 \pm 5$ (range, 19-34) & $26 \pm 5$ (range, I6-34) \\
\hline
\end{tabular}

Abbreviation: BMI, body mass index. 
Table 2 Summary of baseline IOP, change in IOP from group-specific baseline (\%) at each time point, average change in IOP, and maximal change in IOP with $95 \% \mathrm{Cl}$

\begin{tabular}{|c|c|c|c|c|}
\hline & No Treatment & Paracetamol & Acetazolamide & Timolol \\
\hline Baseline IOP (mmHg) & I5.7 (95\% Cl: I4.3 to I7.I) & I 4.8 (95\% Cl: I3.6 to I5.9) & I4.5 (95\% Cl: I2.7 to I6.3) & I4.3 (95\% Cl: I2.8 to I5.8) \\
\hline Change in IOP after & $-2.9 \%$ (95\% Cl: $1.0 \%$ to & $-10.8 \%(95 \% \mathrm{Cl}:-4.9 \%$ to & $-18.8 \%(95 \% \mathrm{Cl}:-12.7 \%$ & $-31.2 \%(95 \% \mathrm{Cl}:-26.7 \%$ to \\
\hline I hour (mmHg) & $-6.7 \%)$, referent & $-16.8 \%), P=0.146$ & to $-24.8 \%), P=0.000$ & $-35.7 \%), P=0.000$ \\
\hline Change in IOP after & $-2.1 \%(95 \% \mathrm{Cl}: 2.9 \%$ to & $13.3 \%$ (95\% Cl: $-8.3 \%$ to & $-26.2 \%(95 \% \mathrm{Cl}:-18.2 \%$ & $-27.7 \%$ (95\% Cl: $-20.7 \%$ to \\
\hline 2 hours $(\mathrm{mmHg})$ & $-7.2 \%)$, referent & $-18.4 \%), P=0.045$ & to $-34.2 \%), P=0.000$ & $-34.8 \%), P=0.000$ \\
\hline Change in IOP after & $-7.6 \%$ (95\% Cl: $-3.9 \%$ to & $-11.8 \%(95 \% \mathrm{Cl}:-5.5 \%$ to & $-24.6 \%(95 \% \mathrm{Cl}:-16.9 \%$ & $-28.7 \%$ (95\% Cl: $-21.1 \%$ to \\
\hline 4 hours $(\mathrm{mmHg})$ & $-11.2 \%)$, referent & $-18.1 \%), P=1.000$ & to $-32.3 \%), P=0.00 \mathrm{I}$ & $-36.2 \%), P=0.000$ \\
\hline Change in IOP after & $-6.9 \%$ (95\% Cl: $-3.6 \%$ to & $-23.9 \%$ (95\% Cl: $-17.8 \%$ & $-26.9 \%(95 \% \mathrm{Cl}:-19.6 \%$ & $-21.3 \%(95 \% \mathrm{Cl}:-13.4 \%$ to \\
\hline 6 hours $(\mathrm{mmHg})$ & $-10.2 \%)$, referent & to -30.1$), P=0.006$ & to $-34.3 \%), P=0.000$ & $-30.0 \%), P=0.030$ \\
\hline $\begin{array}{l}\text { Average change in IOP } \\
\text { over } 6 \text { hours }(\mathrm{mmHg})\end{array}$ & $\begin{array}{l}-4.8 \% \text { (95\% Cl: }-2.6 \% \text { to } \\
-6.9 \%) \text {, referent }\end{array}$ & $\begin{array}{l}-15.7 \%(95 \% \mathrm{Cl}:-9.3 \% \text { to } \\
-22.1 \%), P=0.021\end{array}$ & $\begin{array}{l}-23.1 \%(95 \% \mathrm{Cl}:-16.4 \% \\
\text { to }-29.8 \%), P=0.000\end{array}$ & $\begin{array}{l}-25.3 \%(95 \% \mathrm{Cl}:-19.4 \% \text { to } \\
-31.2 \%), P=0.000\end{array}$ \\
\hline $\begin{array}{l}\text { Maximal change in IOP } \\
\text { within } 6 \text { hours }(\mathrm{mmHg})\end{array}$ & $\begin{array}{l}-9.2 \% \text { (95\% Cl: }-3.2 \% \text { to } \\
-15.3 \%) \text {, referent }\end{array}$ & $\begin{array}{l}-25.9 \%(95 \% \mathrm{Cl}:-16.6 \% \\
\text { to }-35.2 \%), P=0.009\end{array}$ & $\begin{array}{l}-33.8 \%(95 \% \mathrm{Cl}:-25.5 \% \\
\text { to }-42.1 \%), P=0.000\end{array}$ & $\begin{array}{l}-36.8 \% \text { ( } 95 \% \mathrm{Cl}:-31.0 \% \text { to } \\
-42.5 \%), P=0.000\end{array}$ \\
\hline
\end{tabular}

Abbreviations: IOP, intraocular pressure; $\mathrm{Cl}$, confidence interval.

difference in average reduction in IOP when the paracetamol and acetazolamide groups were compared with each other ( $P=0.262)$, which was also the case for the paracetamol and timolol groups $(P=0.094)$.

\section{Maximal change in IOP}

The maximal change in IOP from baseline within the first 6 hours after treatment for the no-treatment group was $-9.2 \%$ (Table 2; Figure 3). It was $-25.9 \%(P=0.009)$ for paracetamol, $-33.8 \%(P=0.000)$ for acetazolamide, and $-36.8 \%(P=0.000)$ for timolol. There was no statistically significant difference in maximal reduction in IOP when the paracetamol and acetazolamide groups were compared with each other $(P=0.691)$, which was also the case for the paracetamol and timolol groups $(P=0.268)$.

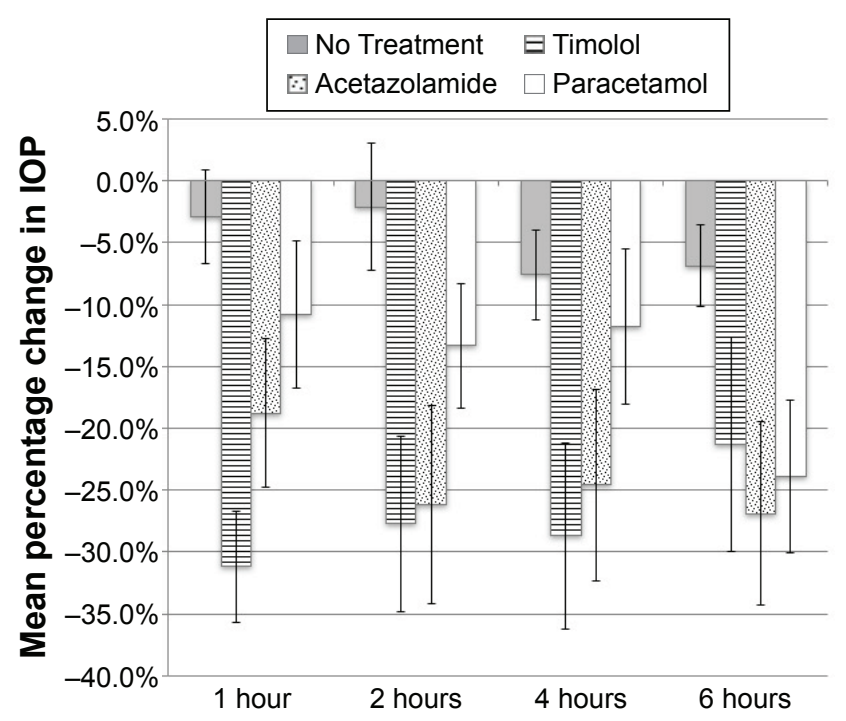

Figure I Mean percentage change in IOP at all time points. Abbreviation: IOP, intraocular pressure.

\section{Discussion}

The study aimed to investigate a possible novel pharmacological pleiotropic property of IV paracetamol and did not aim to investigate paracetamol's ocular hypotensive therapeutic efficacy or suggest it as an alternative glaucoma treatment. For this reason, a "No Treatment" arm was included instead of a placebo arm, to more accurately replicate practical clinical scenarios, and acetazolamide and timolol were included to give clinical perspective to the magnitude of IOP change.

In this study, the administration of $1 \mathrm{~g}$ IV paracetamol was followed by a trend toward a reduction in IOP that was statistically significant at 2 and 6 hours after administration. Although not statistically significant, there was a reduction of $10.8 \%$ in IOP after 1 hour in the

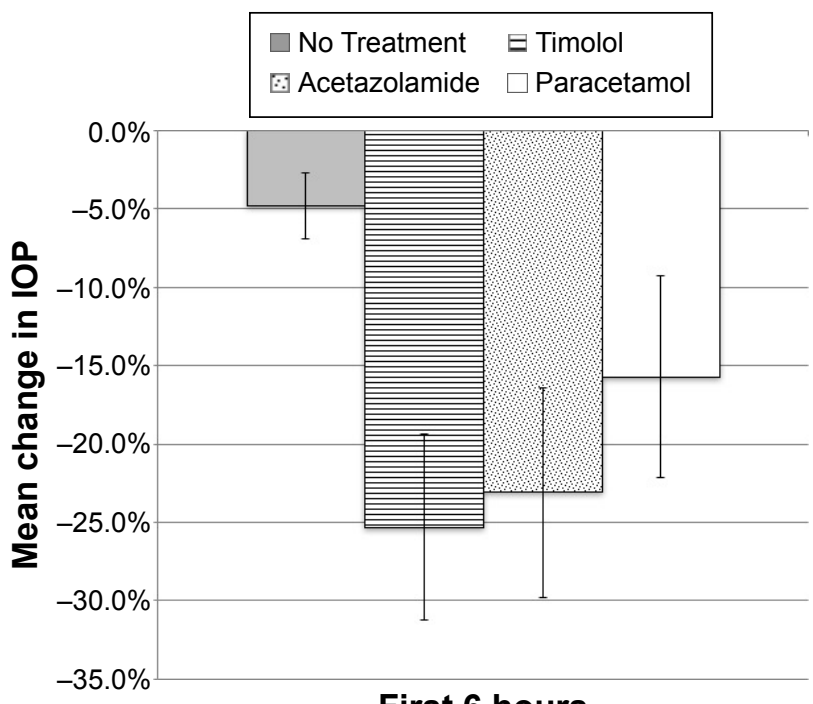

First 6 hours

Figure 2 Mean percentage change in IOP over the first 6 hours after treatment. Abbreviation: IOP, intraocular pressure. 


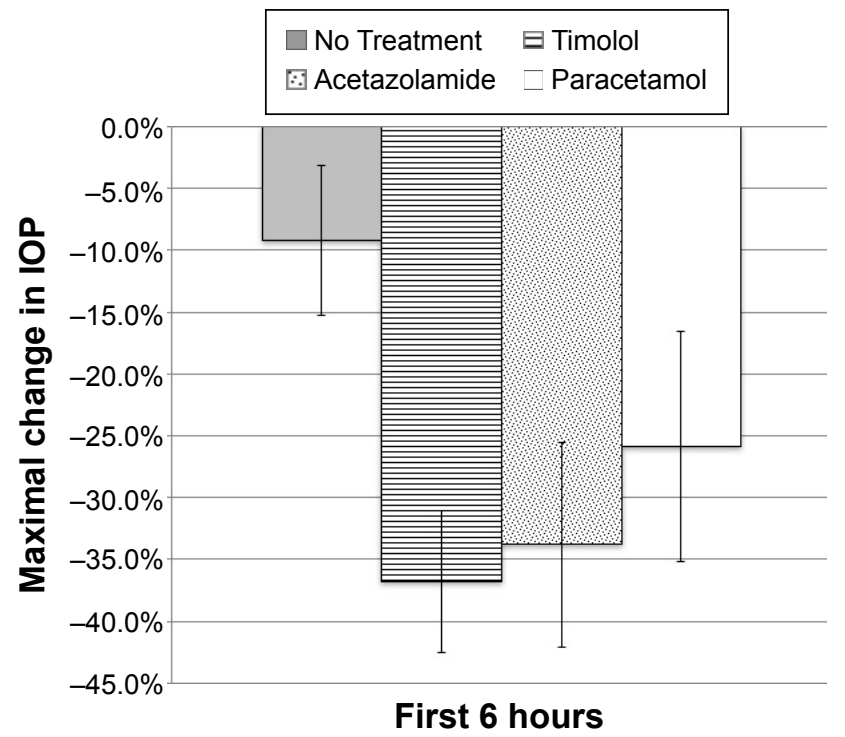

Figure 3 Maximal percentage change in IOP over the first 6 hours after treatment. Abbreviation: IOP, intraocular pressure.

paracetamol group when compared to a $2.9 \%$ reduction in the No Treatment arm.

There was no significant difference in the IOP response when ethnicity, age, or BMI was considered.

The average change in IOP for the paracetamol group over the first 6 hours was $-15.7 \%$, and the maximal change was $-25.9 \%$, which was statistically significant when compared to the no-treatment group. In the No Treatment arm, the $95 \%$ confidence intervals (CIs) included a rise in IOP of $+1.0 \%$ and $+2.9 \%$ at 1 and 2 hours, respectively. Paracetamol and the other two treatment arms showed no such expected change according to their $95 \%$ CI ranges.

The average and maximal reduction in IOP produced by paracetamol was inferior to that of timolol and acetazolamide but statistically significantly more than that of the no-treatment group.

In our no-treatment group, there was an average reduction in IOP over the first 6 hours of $-4.8 \%$ which is similar to the $-5 \%$ found in a meta-analysis of glaucoma therapies and strengthens the validity of our no-treatment group findings. ${ }^{14}$ This expected diurnal phenomenon was adequately accounted for by appropriate statistical analysis. Similarly, the IOP reduction we observed with topical timolol compared well with previous studies by Katz et al and Zimmerman and Kaufman where they showed a reduction in IOP by $-16.8 \%$ at 1 hour, $-26.3 \%$ at 2 hours, and $-27.8 \%$ at 5 hours, and by $-34.4 \%$ at 2 hours, $-44.3 .3 \%$ at 4 hours, and $-27.8 \%$ at 5 hours, respectively. ${ }^{15,16}$

IOP in the paracetamol group showed a downward trend up to 6 hours after treatment, and the reduction in IOP at that point in the paracetamol group was similar to the other two active treatment arms (paracetamol/acetazolamide, $P=1.000$; and paracetamol/timolol, $P=1.000)$.

In general, the IOP-lowering response of a single standard dose of IV paracetamol was inferior to that of both topical timolol and oral acetazolamide.

The need for a follow-up study with repeated doses of IV paracetamol and observations beyond 6 hours is evident. Such multiple doses have been proven safe as the safety profile of IV paracetamol compares well with the oral and rectal formulations, and doses of up to $4 \mathrm{~g}$ daily are rarely associated with hepatotoxicity. ${ }^{4,5}$

Sevoflurane and propofol, among other anesthetic drugs, are known to reduce IOP and should be avoided when performing tonometry in patients under general anesthesia. ${ }^{6,7}$ Similar to sevoflurane and propofol, our results show that IV paracetamol shows a trend toward reducing IOP. Clinicians performing tonometry on patients under general anesthesia should consider enquiring from the anesthetist as to whether IV paracetamol was recently given to the patients before interpreting IOP measurements as patients increasingly receive paracetamol in the perianesthetic period. ${ }^{4}$

Although not a direct finding or conclusion of the study, our results could be explained by the molecular basis of the mechanism of action of paracetamol as proposed by Högestätt et al and Ottani et al., ${ }^{1,2}$

Although probably not widely known, the molecular basis of the ocular hypotensive properties of paracetamol through the ECS is well documented, and the ocular hypotensive properties of its major ligand, anandamide, and the CB1 receptor's abundant distribution in the eye are thoroughly reported..$^{9-13}$

If paracetamol indeed interacts with the ECS, as our findings might support, it may influence our understanding of concurrent paracetamol and antiglaucoma medication use as cannabinomimetics, and some commonly used antiglaucoma therapies employ similar molecular mechanics to reduce IOP, which may influence their efficacy. ${ }^{17,18}$ Further studies to address the theoretical pharmacodynamic interaction of paracetamol with topical $\beta$-blockers and prostamides may also be warranted, as many patients on glaucoma therapy, like their non-glaucomatous counterparts, use prescribed or self-medicating paracetamol.

A high correlation between levels of paracetamol in the serum and levels in the tear film has been shown; this effectively means that the use of systemic paracetamol leads to an unintended ocular topical application thereof which raises interesting questions regarding the ocular hypotensive effects 
of topically applied paracetamol as it has been shown to readily cross the cornea into the anterior chamber. ${ }^{3,19}$

Finally, apart from its role in the regulation of IOP, the ECS has also been implicated in many other ocular conditions and physiological processes. ${ }^{20-27}$ Whether paracetamol, through its apparent association with the ECS, has an effect on these is yet to be investigated.

Although our study did not aim to clinically vindicate the molecular mechanism of action of paracetamol, our findings may provide clinical support for the proposal that paracetamol is indeed a cannabinomimetic.

\section{Limitations}

The findings are a result of a single standard dose of IV paracetamol which limits its application to predicting whether, and by how much, chronic paracetamol use or successive doses of IV paracetamol would change IOP. The introduction of IV paracetamol to clinical practice expands its clinical relevance to more than just that of its chronic oral administration. For the purposes of replicating the administration of IV paracetamol in the perioperative period, a single standard dose was accepted as realistic to this increasingly common scenario.

The exclusion of pediatric patients from the cohort limits the application of the results to an adult population. Whether IV paracetamol, used in pediatric pain management, changes IOP in this special population is still to be investigated.

Not investigating the possible interactions of paracetamol with common topical glaucoma agents is not seen as a limitation of the study but rather an important clinical question that needs to be addressed by future studies.

\section{Conclusion}

Intravenously administered paracetamol shows IOP-lowering properties over the first 6 hours after administration. Clinicians performing IOP measurements in patients who have received IV paracetamol in the preceding 6 hours should interpret these measurements with caution. Further studies are needed to investigate the IOP-changing properties of paracetamol.

\section{Disclosure}

David Meyer is the inventor of a published PCT patent, the application (number W O2009/019555) of which is filed in the name of the Stellenbosch University, South Africa. This patent relates in part to the use of topical paracetamol for glaucoma. Henning van den Heever has no conflicts of interest in this work.

\section{References}

1. Högestätt ED, Jönsson AG, Ermund A, et al. Conversion of Paracetamol to the bioactive N-acylphenolamine AM404 via fatty acid amide hydrolase-dependent arachidonic acid conjugation in the nervous system. J Biol Chem. 2005;280:31405-31412.

2. Ottani A, Leone S, Sandrini M, et al. The analgesic activity of Paracetamol is prevented by the blockade of cannabinoid $\mathrm{CB}_{1}$ receptors. Eur J Pharmacol. 2006;531:280-281.

3. Mohamed N, Meyer D. Intraocular pressure-lowering effect of oral Paracetamol and its in vitro corneal penetration properties. Clin Ophthalmol. 2013;7:219.

4. White F. The changing role of non-opioid analgesic techniques in the management of postoperative pain. Anesth Analg. 2005;101(5 Suppl): S5-S22.

5. Candiotti KA, Bergese SD, Viscusi ER, et al. Safety of multipledose intravenous Paracetamol in adult inpatients. Pain Med. 2010;11: 1841-1848.

6. Schafer R, Klett J, Auffarth G, et al. Intraocular pressure more reduced during anesthesia with propofol than with sevoflurane: both combined with remifentanil. Acta Anaesthesiol Scand. 2002;46:703-706.

7. Kataria B, Epstein R, Bailey A, et al. A comparison of sevoflurane to halothane in pediatric surgical patients: results of a multicenter international study. Pediatr Anaesth. 1996;6:283-292.

8. Ayoub SS, Colville-Nash PR, Willoughby DA, et al. The involvement of a cyclooxygenase 1 gene-derived protein in the antinociceptive action of Paracetamol in mice. Eur J Pharmacol. 2006;538:57-65.

9. Vettor R, Pagotto U, Pagano C, et al. Here, there and everywhere: the endocannabinoid system. J Neuroendocrinol. 2008;20(Suppl 1):iv-vi.

10. Katona I, Freund TF. Multiple functions of endocannabinoid signaling in the brain. Annu Rev Neurosci. 2012;35:529-558.

11. Brown AJ. Novel cannabinoid receptors. Br J Pharmacol. 2007;152: 567-575.

12. Chen J, Matias I, Dinh T, et al. Finding of endocannabinoids in human eye tissues: implications for glaucoma. Biochem Biophys Res Commun. 2005;330:1062-1067.

13. McIntosh BT, Hudson B, Yegorova. Agonist-dependent cannabinoid receptor signaling in human trabecular meshwork cells. Br J Pharmacol. 2007;152:1111-1120.

14. Van der Valk R, Webers CAB, Schouten JSAG, et al. Intraocular pressure-lowering effects of all commonly used glaucoma drugs: a meta-analysis of randomized clinical trials. Ophthalmology. 2005;112: $1177-1185$.

15. Katz IM, Hubbard WA, Getson AJ, et al. Intraocular pressure decrease in normal volunteers following Timolol ophthalmic solution. Invest Ophthalmol Vis Sci. 1976;15:489-492.

16. Zimmerman TJ, Kaufman HE. Timolol, dose response and duration of action. Arch Ophthalmol. 1977;95:605-607.

17. Hudson BD, Beazley M, Szczesniak A, et al. Indirect sympatholytic actions at $\beta$-adrenoceptors account for the ocular hypotensive actions of cannabinoid receptor agonists. J Pharmacol Exp Ther. 2011;339: $757-767$.

18. Romano MR, Lograno MD. Evidence for the involvement of cannabinoid CB1 receptors in the bimatoprost-induced contractions on the human isolated ciliary muscle. Invest Ophthalmol Vis Sci. 2007;48: 3677-3682.

19. Lifshitz M, Weinstein O, Gavrilov V, Rosenthal G, Lifshitz T. Paracetamol (Paracetamol) levels in human tears. Ther Drug Monit. 1999; 21:544.

20. Romano MR, Lograno MD. Cannabinoid agonists induce relaxation in the bovine ophthalmic artery: evidences for CB1 receptors, nitric oxide and potassium channels. Br J Pharmacol. 2006;147:917-925.

21. Lalonde MR, Jollimore CA, Stevens K, et al. Cannabinoid receptormediated inhibition of calcium signaling in rat retinal ganglion cells. Mol Vis. 2006;12:1160-1166.

22. Wei Y, Wang X, Wang L. Presence and regulation of cannabinoid receptors in human retinal pigment epithelial cells. Mol Vis. 2009;15:1243. 
23. Iribarne $\mathrm{M}$, Torbidoni $\mathrm{V}$, Julián $\mathrm{K}$, et al. Cannabinoid receptors in conjunctival epithelium: identification and functional properties. Invest Ophthalmol Vis Sci. 2008;49:4535-4544.

24. Yang H, Wang Z, Capo-Aponte JE, et al. Epidermal growth factor receptor transactivation by the cannabinoid receptor $(\mathrm{CB} 1)$ and transient receptor potential vanilloid 1 (TRPV1) induces differential responses in corneal epithelial cells. Exp Eye Res. 2010;91:462-471.

25. Yazulla S. Endocannabinoids in the retina: from marijuana to neuroprotection. Prog Retin Eye Res. 2008;27:501-526.
26. Matias I, Wang JW, Moriello AS, et al. Changes in endocannabinoid and palmitoylethanolamide levels in eye tissues of patients with diabetic retinopathy and age-related macular degeneration. Prostaglandins Leukot Essent Fatty Acids. 2006;75:413-418.

27. Nucci C, Gasperi V, Tartaglione R, et al. Involvement of the endocannabinoid system in retinal damage after high intraocular pressure-induced ischemia in rats. Invest Ophthalmol Vis Sci. 2007;48:2997-3004.

\section{Publish your work in this journal}

Clinical Ophthalmology is an international, peer-reviewed journal covering all subspecialties within ophthalmology. Key topics include: Optometry; Visual science; Pharmacology and drug therapy in eye diseases; Basic Sciences; Primary and Secondary eye care; Patien Safety and Quality of Care Improvements. This journal is indexed on

Submit your manuscript here: http://www.dovepress.com/clinical-ophthalmology-journal

\section{Dovepress}

PubMed Central and CAS, and is the official journal of The Society of Clinical Ophthalmology (SCO). The manuscript management system is completely online and includes a very quick and fair peer-review system, which is all easy to use. Visit http://www.dovepress.com/ testimonials.php to read real quotes from published authors. 